\author{
Os solteirões \\ dentro ou fora do armário? \\ Micaela Sá da Silveira \\ Antonio de Pádua Dias da Silva
}

SILVEIRO, MS., and SILVA, APD. Os solteirões: dentro ou fora do armário?. In: MITIDIERI, AL., and CAMARGO, FP., orgs. Literatura, homoerotismo e expressões homoculturais [online]. Ilhéus, BA: Editus, 2015, pp. 191-215. ISBN 978-85-7455-442-6. Available from SciELO Books $<$ http://books.scielo.org $>$.

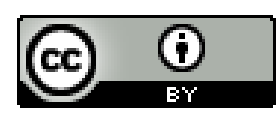

All the contents of this work, except where otherwise noted, is licensed under a Creative Commons Attribution 4.0 International license.

Todo o conteúdo deste trabalho, exceto quando houver ressalva, é publicado sob a licença Creative Commons Atribição 4.0.

Todo el contenido de esta obra, excepto donde se indique lo contrario, está bajo licencia de la licencia Creative Commons Reconocimento 4.0. 


\title{
OS SOLTEIRÕES: DENTRO OU FORA DO ARMÁRIO?
}

\author{
Micaela Sá da Silveira ${ }^{1}$ \\ Antonio de Pádua Dias da Silva²
}

\section{Olhando por entre as brechas}

A família reunida na sala. Os amigos que se encontram por um chamado especial. Uma aula na faculdade. Uma festa em que o pai chega de repente. Um telefonema pedindo explicações. Uma carta que denuncia. Essas são algumas situações em que os sujeitos são postos - ou expostos - para falar de si, para esclarecerem à sociedade, aos parentes, amigos, esposas e maridos: o que desejam, afinal?

Situações como essas são constantes na sociedade e representadas na literatura, tornando assim a categoria do "armário" passível de questionamentos: O que é o "armário"? Por que os sujeitos precisam sair do "armário"? Por que esconder-se em um "armário"?

1 Graduada em Letras pelas Universidade Estadual da Paraíba. Mestra em Literatura e Interculturalidade pela mesma Instituição. E-mail: <micaelauep@hotmail.com>.

2 Professor Doutor do Departamento de Letras e Artes da UEPB e do Programa de Pós-Graduação em Literatura e Interculturalidade da mesma Instituição.

E-mail:<magister.padua@hotmail.com>. 
A quem pertence esse esconderijo? Para quê gritar ao mundo quem e quais são os nossos objetos de desejo? O que vem a ser assumir-se e por que temos de fazê-lo?

Diante de tantas inquietações, e claramente estimulados pela discussão apresentada por Eve Sedgwick (2007), no texto Epistemologia do armário, em que a autora nos permite (re)pensar esse espaço, no qual muitos sujeitos homoeroticamente inclinados são colocados ou do qual são retirados, além de refletir sobre os limites do público e do privado numa relação entre pessoas do mesmo sexo, debruçamo-nos sobre a obra de Gasparino Damata, intitulada Os solteirões (1975), a fim de problematizar esse "armário", levando em consideração o limiar entre estar/permanecer/sair deste lugar, para os personagens do conto.

Tomamos como objeto de estudo a obra damatiana, por colocar em evidência a possibilidade das múltiplas masculinidades para os sujeitos que mantêm relações homoeróticas. A discussão teórica que subsidia as masculinidades, no plural, foi embasada nos apontamentos de Elizabeth Badinter (1993) e Sócrates Nolasco (1993, 1997), tendo-se em vista que esses teóricos apresentam questionamentos acerca da relação do que é ser um homem, de como é/ foi construído esse sujeito nos vários contextos históricos, social e cultural. Igualmente, os estudos das categorias binárias como uma invenção, apresentados por Katz (1996), foram de suma importância para o debate sobre as relações hetero (superior) versus homo (inferior), 
que, muitas vezes, atuam como obstáculo para que os homens se entreguem aos desejos homoeróticos.

\section{Adentrando ou saindo dos possiveis "armários"?}

Entabular uma discussão em torno do "armário", considerando a efetiva visibilidade que as chamadas minorias vêm ganhando com o passar do tempo, requer pensar primeiramente: de qual "armário" estamos falando? A que objeto essa metáfora está se referindo? Comecemos a pensar que há, no minimo, duas direções para tal metáfora: a) popularmente costumou-se afirmar que os sujeitos inclinados homoeroticamente e que o declaravam, perante a sociedade o desejo por seu igual, estavam saindo do "armário", ou seja, estes indivíduos não escondiam a quem seu desejo "proibido" estava direcionado; b) o "armário", enquanto dispositivo político, do qual as multidões de minorias ${ }^{3}$ precisam sair, para que tenham uma representação social.

Buscando compreender as possibilidades de interpretação para a metáfora apresentada por Sedgwick (2007), encontramos na obra de Damata um campo proficuo para ampliar tal discussão. Os Solteirões (1975) apresenta os

3 Fazemos referência ao estudo de Beatriz Preciado (2011), no qual as minorias são apresentadas como multidões que se aglomeram nas diferenças, no direito de ser o que não se nomeia, ou simplesmente como uma multidão Queer. "As minorias sexuais tornam-se multidões. 0 monstro sexual que tem por nome multidão torna-se queer” (PRECIADO, 2011, p. 14). 
modos pelos quais os sujeitos masculinos se relacionam com a possibilidade do "armário", algumas vezes diretamente, outras vezes através da imposição ou necessidade de "revelarse", apresentando o assumir-se como objeto de debate dentro do núcleo a que pertencem os personagens. Nos contos de Damata, o "armário" está inserido nas relações entre os michês $^{4}$ com idades e posições sociais diferentes e que possuem desejo homoerótico manifestado ora em relacionamento mais duradouro, ora em relações de amor e ciúme, ou mesmo no desejo carnal, por exemplo.

Vamos aos contos. Em "Paraíba", há um diálogo entre dois rapazes: o narrador personagem, que relata sua saída da Paraíba para morar na cidade do Rio de Janeiro e sua experiência no cinema de "pegação"; e seu interlocutor, Seu Zé Orlando, que, no decorrer do texto, não apresenta nenhuma opinião, apenas ouve o narrador e partilha com ele as mesmas experiências de mudança de cidade e de frequentar o mesmo cinema. Percebemos que tanto o narrador personagem - caracterizado pela ambivalência de

40 conceito de michê que adotamos baseia-se nas concepções apresentadas por Perlongher (1987): a) nomeando o ato de prostituir-se, desenvolvido por qualquer sujeito; b) a prostituição como sendo efetivada por um homem másculo, que em seu estereótipo prevalece a virilidade. Salientemos que, na obra em análise, os michês nem são prostitutos, nem são másculos viris, conforme apontam os desdobramentos do conceito de Perlongher. Nos contos, a negociação está relacionada com a compra/paga do afeto e não apresentam os personagens como sendo efeminados ou puramente viris. 0 que temos são homens comuns que mantêm relações com outros homens. A diferença está, muitas vezes, na idade e/ou na condição financeira. 
sua masculinidade, como discutimos em outro momento (SILVEIRA, 2012) - quanto Seu Zé Orlando, não são gays, nem adotam tal masculinidade e, por isso, não teriam motivos para saírem do "armário" e expor algo que eles não são. Mesmo mantendo relações sexuais e afetivas com outros iguais, isso não os torna sujeitos inclinados homoeroticamente, se levarmos em consideração que só pode assumir-se gay, se o desejo homo for subjetivado pelo sujeito.

É interessante perceber que os personagens afirmam, constantemente, serem "de mulher", ou seja, o discurso deles é que o "negócio" realizado é para fins profissionais e que, na verdade, preconizam a relação com mulheres, embora pouco efetivada devido ao alto custo para mantê-las, pois "mulher é luxo. E luxo só rico é que pode ter" (DAMATA, 1975, p. 7). Neste sentido, justifica-se o fato desses personagens não assumirem nenhuma identidade gay, pois não se reconhecem dessa forma e sim como homens que frequentam o cinema e sentem-se bem: "se quisesse viver disso, podia até deixar de trabalhar, hoje mesmo" (DAMATA, 1975, p. 11), apontando o "negócio do michê"5 como uma fonte de renda.

Social e culturalmente, há uma ideia de que qualquer desejo - afetivo ou sexual - direcionado para seu igual é expressão de um sujeito gay, mas acreditamos que as categorias heterossexuais e homossexuais são, na verdade, imposições criadas por grupos hegemônicos, vislumbrando

5 Expressão utilizada por Perlongher (1987) e homônima ao título do livro. 
enquadrar as multidões de minorias para assim estigmatizá-las. Diante disso, nos questionamos: afinal, o que define o sujeito ser ou não gay? Sedgwick (2007) refere-se ao sujeito gay como sendo aquele que assume sua identidade e carrega as consequências que isso traz:

[...] quão problemático no presente é
o conceito mesmo de identidade gay e
também quão intensa é a resistência
a ela e o quanto a autoridade sobre
sua definição se distanciou da própria
pessoa gay - ele ou ela (SEDGWICK,
2007 , p. 38 ).

Ainda no conto "Paraíba", percebe-se que o narrador personagem não simpatiza, nem se sente atraído pelos sujeitos que são assumidos como gays e efeminados, que estão fora do "armário". O desinteresse do personagem fica claro ao afirmar que "não costumo dar atenção a essas bichas escandalosas, que ficam para cima e para baixo e que falam o tempo todo" (DAMATA, 1975, p. 11).

Em outros contos, percebemos a evidência dessa aversão dos sujeitos homoeroticamente inclinados para com os sujeitos que estão fora do "armário", bem como a preservação que estes personagens têm quanto à sexualidade. No conto $A$ desforra, o que temos no enredo é Ferreira, um dentista que busca vingar-se do seu "caso", por causa de uma traição. O seu "rapaz" o traiu com uma mulher, mas voltou a procurá-lo, quando ela o trocou por outra mulher. É interessante perceber que o dentista 
protege sua identidade e, em seu ambiente de trabalho, por exemplo, não há "nada de exageros, de decoração afrescalhada, porque Ferreira, ao contrário de alguns companheiros, evitava ao máximo tudo que pudesse denunciá-lo, bichices desnecessárias, como costumava dizer" (DAMATA, 1975, p. 132) e, ainda, é bastante enfático no que se refere à exposição pessoal ou saída do "armário" "- 'Detesto viadagem em público. Frescura, só em casa; ou dentro de quatro paredes"' (DAMATA, 1975, p. 132, grifo do autor).

Diante da postura do dentista, percebese que não há saída do "armário", pois entendemos que esse dispositivo só existirá em situação de risco, ou seja, perante a sociedade, que não aceita as relações que fogem do padrão por ela definido. Ora, se há "frescura só em casa", isso implica em dizer que apenas as pessoas que estão próximas - parentes e amigos - sabem das relações entre iguais vivenciadas por Ferreira.

A postura do dentista denota: o quanto é forte essa ideia de público e privado para os sujeitos homoeróticos, as situações que devem (será que devem?) ser mantidas em segredo, guardadas a "sete chaves", aquilo que a sociedade pode saber, ou que ela quer ouvir. Outro exemplo dessa situação está exposto no final do conto O voluntário que, segundo Howes (2010), narra uma história semelhante ao romance The Sergeant (1958), de Dennis Murphy: 
[...] um sargento militar apaixona-se por um praça sob seu comando. No romance americano, o soldado reage violentamente contra o assédio do sargento, que, totalmente isolado, acaba se suicidando. A novela de Damata tem o mesmo enredo, mas o desenvolvimento do tema é completamente diferente (HOWES, 2010, p.184).

O sargento do texto brasileiro considerava as bichas

[...] elementos indesejáveis - 'a vergonha da classe' [queria que] desaparecessem o mais depressa possivel do cenário. Não suportava gente de saia, mas também não tolerava bicha. Veado efeminado, que queria ser mulher a todo custo (DAMATA, 1975, p. 123 - grifo do autor).

O discurso apresentado por esse personagem afirma o pensamento da ambivalência do "armário", uma vez que, se os gays saem do "armário" e expõem seus desejos, performatizam sua masculinidade como bem desejam, são rechaçados pelos gays que não se assumem. Estes, popularmente conhecidos como enrustidos, são criticados pelos colegas que preferem revelar o segredo. Esse retrato da década de 1970, apresentado através dos contos, é uma realidade presente até os dias de hoje, fazendo com que os sujeitos homoeroticamente inclinados se encontrem entre os que saem dos "armários" e os enrustidos. 
Para além dos personagens que não saem do "armário", Damata também nos coloca diante de personagens que saem, ou melhor, são levados a sair do "armário", como em Fábula. Neste conto, é apresentada uma família tradicional, dentro dos padrões exigidos socialmente, no entanto, essa característica é apenas aparente, uma vez que no decorrer da leitura, o personagem, que mais protesta pela manutenção da moral e bons costumes, fora frustrado no que diz respeito ao afeto que sentiu pelo seu igual.

O enredo apresenta a experiência do "armário" vivenciada por Luciano, o filho caçula de Otávio, que acontece por meio de uma foto sua publicada em O Cruzeiro, "na qual aparecia com destaque no meio de um grupo de rapazes suspeitos no baile de carnaval da segunda-feira no Iate" (DAMATA, 1975, p. 164). Ao saber que essa foto já estava em domínio público, Luciano entra em pânico, uma vez que conhece o pai que tem: extremamente exigente, correto, digno, respeitador, que

[...] nunca levantara a mão para bater em filho, mas em questão de moral, qualquer coisa, por menor que fosse, capaz de atingir a honra da família, uma verdadeira fera, capaz de matar, de fazer qualquer loucura (DAMATA, 1975, p. 164-165).

Além disso, tinha um irmão mais velho que se comportava tal qual o pai e sabia-se preferido, por isso tomava atitudes semelhantes, 
para que o pai se orgulhasse dele. Diante dessa saída do "armário", o irmão expressava em seu rosto "um mapa ilhado de revolta e ódio" (DAMATA, 1975, p. 168). Diante de tal realidade, é compreensivel a reação de Luciano. O desmaio, o choro compulsivo ao encontrar o pai, que não nega o seu desagrado para com o filho: "- Eu preferia mil vezes vê-lo morto, meu filho, mil vezes morto a ter que ficar sabendo que você se tornou... também isso!" (DAMATA, 1975, p. 166).

É notório, diante das falas e da reação do pai, em um primeiro momento, o quanto tal revelação o incomodara e o quanto ele despreza esse tipo de comportamento. Essa atitude deixa clara uma questão: o legado de supremacia histórico e social que a heterossexualidade possui diante da homossexualidade. Um estudo relevante nesse aspecto é o de Katz (1996) que desconstrói a ideia de superioridade e apresenta a heterossexualidade como invenção criada para manter a homossexualidade como sua subordinada. Para ele, a heterossexualidade foi "construída bastante recentemente como o que é muito antigo: a heterossexualidade é uma tradição inventada" (KATZ, 1996, p. 183).

Nesse sentido, assumir uma posição diferente da imposta pela heterossexualidade é estar à espera de condenação. Segundo Segdwick,

[...] o "armário" pode ser entendido como um dispositivo de regulação da vida de gays e lésbicas que concerne, também, aos heterossexuais e seus 
privilégios de visibilidade e hegemonia de valores (SEGDWICK, 2007, p. 19 grifo nosso).

Ou seja, tanto sair do "armário" quanto manter-se nele está atrelado diretamente à relação binária do superior versus inferior, em que o favorecido sempre será o "superior", o detentor do poder, o dominante. Ao sair do "armário", "pede-se licença" para gritar ao mundo suas escolhas e, ao se manter no "armário", está escondendo da sociedade aquilo que desestabiliza a ordem por ela imposta.

Nessa perspectiva, é importante salientar que essa situação de "armário", vivenciada por Luciano, não aconteceu por causa de sua vontade de gritar ao mundo sua subjetividade. Lembremos que uma foto sua saiu em uma revista sem que o mesmo soubesse, sem que ele tivesse escolhido que suas relações entre iguais fossem reveladas. Assim, entendemos que o "armário" é uma metáfora criada e imposta pelos grupos majoritários a fim de classificar, apontar e julgar as minorias.

Voltemos ao texto damatiano. O clímax do conto se dá quando Otávio, percebendo e vendo seu filho no ápice do desespero, decide partilhar com ele o seu segredo mais íntimo. A fim de consolá-lo, inicia a confissão:

- O que o seu pai quer, e isso é o que todo pai cuidadoso deseja para um filho - continuou -, é vê-lo no caminho certo, no caminho que a sociedade traçou para todos nós, você compreende?' 
- Sabe, Luciano, quando eu era de sua idade também tive um amigo...'

$[\ldots]$

- Eu e o João Henrique nos tornamos inseparáveis, logo que nos conhecemos no colégio. Namorávamos duas pequenas - adiantou - que moravam na mesma rua, no Jardim Botânico. Pois bem, éramos tão amigos e gostávamos tanto um do outro que nos beijávamos na boca' (DAMATA, 1975, p. 169-170 - grifos do autor).

Tal como deveríamos presumir, a reação de Luciano foi de não acreditar, tendo em vista que a figura que ele tinha em sua frente era do homem ético, moral e que honra a família e o lar, que acabara de julgar seu filho por se relacionar com outro rapaz, sendo no mínimo incoerente. Para além da confissão do pai de Luciano, o que percebemos é o desejo do pai de respeitar os caminhos socialmente predefinidos e não deixar fluir o desejo do indivíduo. É interessante observar que Otávio, o pai de Luciano, também fora levado para o caminho do "bem", socialmente falando, através da exigência de seu pai, o avô de Luciano, que o obrigou, através de uma conversa na mesma biblioteca em que a cena se passa agora, a acabar com aquela relação de Otávio e João Henrique. A reação dele foi a seguinte:

[...] fiquei chocado e ao mesmo tempo revoltado, e me encontrava com ele [João Henrique] às escondidas, no Jardim botânico. Na ocasião - adiantou - 
o velho me fez ver que aquela amizade era perigosa, não podia nunca dar certo. E o curioso é que me comportei exatamente como você, agora. E de que maneira você poderia se comportar nessa sua idade e numa situação mais ou menos parecida? (DAMATA, 1975, p. 171).

Notadamente, a "saída do armário" vivenciada por Luciano foi impactante, pois não ocorreu por sua necessidade de assumir um posicionamento gay. Além disso, naquele momento, ouviu de seu pai a declaração sobre a experiência frustrada que tivera em sua adolescência, tentando mostrar ao filho que a situação poderia ser revertida. Entendemos que o objetivo da hipócrita confissão foi apenas para que Luciano percebesse, em Otávio, um vencedor, por ter superado aquele caminho errado ao seguir as regras que o seu pai, avô de Luciano, impusera: sublimar o desejo que tinha por seu amigo João Henrique e se adequar à ordem social, fazendo com que a vida seguisse no padrão esperado pela sua família:

- Pois é, reatei o namoro com a sua mãe, fui trabalhar no escritório de advocacia do seu tio Olavo e à noite estudava, fui um dos primeiros alunos da minha turma, na Faculdade. Casei uma semana após a minha formatura e até hoje não me arrependi. Sou um homem feliz, realizado - disse em conclusão, com a voz grave, nostálgica, já de pé, pronto para sair (DAMATA, 1975, p. 171). 
Diante do sermão apresentado por Otávio, a atitude de Luciano é seguir o mesmo caminho que seu pai: cumprir o papel que se espera de uma pessoa do sexo masculino. Badinter (1993), em $X Y$ : sobre a identidade masculina, apresenta-nos esclarecimentos acerca desse sujeito masculino, de como nasce e o que é (ou vem a ser) esse homem, construído com grande esforço e trabalho, pois a virilidade necessária para esse tal sujeito não é facilmente adquirida. O que há, de fato, é uma constante luta para que ele seja tudo o que não o faz ser mulher: forte, bruto, insensivel, másculo, provedor.

A fim de cumprir o que o pai lhe sugeriu para que voltasse a ser um homem, Luciano decide reatar o namoro com uma menina e fazer plano para serem "felizes para sempre", porém, no caminho, a sua vida é interrompida em um acidente, que é descrito no conto da seguinte forma:

Dobrando a esquina numa curva fechada, perigosa, entrou na São Clemente, sentindo na velocidade que imprimia à maquina um prazer infinito, um estranho orgasmo fruto de suor e vento, que lhe molhou as calças; e a uma quadra de atingir o Santo Inácio, deu-se o inesperado. Procurou desviar-se de um caminhão feireiro que de repente surgiu por trás do bonde, mas bateu na parte lateral da carroceria de um carro-tanque da Esso que minutos antes deixara para trás; cuspido na calçada, esfacelou o crânio num poste e morreu instantaneamente, sem dar 
tempo ao padre Bonifácio de colocar a vela na sua mão e recomendar-lhe a alma (DAMATA, 1975, p. 173).

A morte de Luciano não representa tão somente perder a vida, e sim, uma morte alegórica, que nos faz pensar nas pessoas que morrem ou estão morrendo ao tentar camuflar seus desejos e manter-se no "armário", assumindo um papel que não é o seu, frustrando-se a cada dia. Além disso, podemos perceber que essa morte, enquanto materialidade fisica, realmente, pode configurar-se como a chamada "moral da história" que, frequentemente, está presente no gênero textual que intitula o conto analisado, ou seja, o resultado para quem infringe as regras postas, social e culturalmente, é a morte.

O desfecho do conto nos faz pensar sobre esse assumir-se. Ora, o pai só confessou sua experiência ao filho com o intuito de mostrar-lhe que, apesar de ter "agido mal", conseguiu voltar aos caminhos corretos, seguindo os conselhos do avô de Luciano, apresentando essa experiência como uma forma de seu filho escapar do mal, que o assolava. Percebemos, com isso, que o "armário" é um lugar de tensão, e que sair dele gera confronto, mas permanecer nele também o gera, e ser colocado fora dele não é o que traz tranquilidade, uma vez que a própria noção de "armário" é proveniente de uma ação social verticalizada.

Um questionamento importante que perpassa todo o assunto do "armário" é saber: de 
fato, ele existe para os sujeitos homoeroticamente inclinados ou é uma criação de um grupo para enclausurar tudo aquilo que foge às normas sociais? É notório que, frequentemente assumir e não assumir está ligado a uma regulação do grupo dominante, e não é fruto da subjetividade de cada sujeito. Essa regulação é posta de tal forma que ficar no "armário" pode ser visto como permanecer no lugar do medo, da covardia e da insegurança, mas também pode ser visto como estar no conforto, uma estratégia de se manter em um lugar no qual os influxos externos não atingem o sujeito.

Vale a pena ressaltar que o "armário" não é apenas um dispositivo gay, pois cada multidão de minoria tem seu "armário", tem aquilo que prefere ou precisa guardar para evitar a exposição diante de uma sociedade que julga o comportamento dos indivíduos. Ocultar evita uma série de reações preconceituosas. Entretanto, até que ponto é importante essa rejeição de si, e de sua identidade? Até que ponto é válido o esconder-se de si? Ressaltemos que essa ambivalência entre a "rejeição de si" e o “assumir-se" está diretamente ligada aos sujeitos que desejam seguir a vida a partir de uma postura gay, que desejam vivenciar plenamente sua subjetividade, definida como tal, dentre os que têm consciência dessa masculinidade.

Voltando aos contos de Damata, ainda relacionando as questões de público e privado, um conto em especial nos coloca diretamente diante da relação que não está apenas no âmbito dos iguais. Em $O$ inimigo comum, 
conhecemos um casal, um velho da Marinha e seu jovem amante Otávio, que se atrasa para seu encontro com o velho devido a uma conversa que tivera com sua namorada. O velho,

[...] fazia parte de um grupo de senhores que costumavam ficar sentados na praça até altas horas da noite conversando; sujeitos que já tiveram o seu tempo [de michê] e hoje vivem de saudade e da recordação (e nada para eles presta) (DAMATA, 1975, p. 51).

Enquanto esperava seu amante, o ambiente é descrito, a Cinelândia, com seus encantos e os mais diversos personagens e performances masculinas.

Uma descrição em especial nos chama atenção, enquanto somos convidados a esperar junto com o velho a chegada de seu amante:

Num banco mais afastado, quase no fim da praça, dois senhores conversavam já há bastante tempo. Por fim se levantaram e saíram despreocupadamente. Eram caso, viviam juntos há trinta anos ou mais, verdadeiro recorde de sobrevivência debaixo do mesmo teto numa época em que mesmo os casamentos entre homem e mulher já não duravam muito, desfaziam-se por qualquer tolice. Onde quer que um estivesse o outro também estava (ou não tardava a aparecer), sendo que o mais novo costumava andar por toda a parte com o braço por cima do outro, numa prova de desinibição e 
carinho, e consta que entre eles nunca houve infidelidade ou brigas grossas (DAMATA, 1975, p. 52).

Damata apresenta esses companheiros como modelo para outros casais, sejam eles hetero, homo ou bissexuais. Estes personagens são significativos para o livro, na nossa leitura, por se tratar de um par em que o "armário" está aberto independente do que a sociedade possa dizer deles, sem nada a esconder, assumindo todo o risco de apresentar ao mundo a subjetividade gay e enfrentando o perigo que o preconceito dos outros pode causar.

Voltemos ao velho marinheiro e seu amante Otávio, que, finalmente, ao chegar ao encontro, põe em pauta aquele que se tornou o inimigo comum das relações masculinas homoeróticas, na visão do velho marinheiro: a mulher. O velho, que, por algumas vezes, precisou manter relações com mulheres por conta do cargo que ocupara, lembra que "só ia mesmo com uma puta lá da zona quando não havia mais jeito, ia a bem dizer por obrigação, pra despistar" (DAMATA, 1975, p. 57). Evidente que esse despistar se refere ao fato de os outros colegas não perceberem a sua repugnância para com as mulheres.

Apesar de toda aversão que é descrita em várias páginas, ao perceber que Otávio se encontrara apaixonado por uma mulher, caindo em choro pelo sentimento que o tomava, o velho, movido por essa comoção e, notadamente, para consolar seu "rapaz", refaz seu discurso e afirma: 
- Sou contra mulher, é sem vergonha, que não faz por onde merecer, meu camarada. Depois, cada qual tem seu gosto, respeito o gosto alheio. Quer saber mais? Já estou velho, cansado. Qualquer dia desses bato a bota, não, vou pro outro mundo, como se diz. E como é que você vai ficar, vamos, me responda? Sem ter quem tome conta de você, quem faça as coisas pra você (DAMATA, 1975, p. 62).

Observemos que, posto entre o rapaz objeto de seu desejo e o seu "inimigo", o velho recua e mostra-se mais aberto a essa relação de Otávio com a mulher, vislumbrando, sobretudo, que seu rapaz tenha alguém para cuidar dele, independente de quem seja. Otávio se coloca diante de dois desejos diferentes tanto dele para com seu velho, quanto para com sua namorada. No entanto, não podemos considerar que vivenciar esses desejos o coloque fora do "armário", tendo em vista que, em nenhum momento, Otávio assume uma subjetividade gay, apenas dá vazão aos desejos.

$\mathrm{O}$ fato de os personagens direcionarem o desejo para homens e mulheres também está presente em "Muro de silêncio", pois o fuzileiro, amante do velho, engravidara uma mulher, tornara-se pai, mas não deixara de manter o relacionamento com o seu amante, que, por muitas vezes, foi quem financiou suas despesas. Ou seja, a relação de afeto e desejo era existente e duradoura, mas o fuzileiro não precisava assumir-se gay, se não o era. Nomear, enquadrar e 
engessar as relações, ao invés de simplesmente deixar que as sensações tomem conta, essa é a realidade que temos no que diz respeito aos afetos e ao que conseguimos ver deles. Ver e julgar, verbos que estão sempre acompanhados dos "armários" que nos cercam.

Em O crucificado, o "armário" é apresentado, via confissão dos pecados dos sujeitos homoeroticamente inclinados, para o padre da igreja católica. Além de toda a relação de amizade entre José Tércio e Dom Vicente, o enredo desse conto traz a confidência do amor entre iguais e as suas consequências. No momento em que José Tércio confessa ao padre que mantinha relações com seu igual, ele o fazia pela necessidade de arrancar da alma o que lhe afligia, a sensação que lhe tomara era de quem acaba de fazer papel de ridículo:

\footnotetext{
[...] fora ter com Dom Vicente logo cedo, antes de entrar no escritório, a fim de livrar-se de um problema que o atormentava. E não apenas para se confessar ou se converter, como era o desejo de muitos. E também do próprio beneditino, talvez (DAMATA, 1975, p. 177).
}

Em contrapartida, o padre surpreende ao afirmar-lhe que

- Essas coisas não podem ficar assim tão ocultas, em segredo absoluto. É muito perigoso. A pessoa precisa desabafar com alguém, livrar-se do 
peso. Há sempre um amigo que ajuda, no qual a gente confia um pouco mais (DAMATA, 1975, p. 184).

A posição do padre é acolhedora e confortante para com seu confidente e, consequentemente, para com todos aqueles que o procuravam para desabafar, mas não saíam de lá totalmente ilesos, tendo em vista que o padre apontava os que desejavam seu igual como responsáveis pelo preconceito sofrido: "mas se procediam assim, é porque sabiam que iam viver a vida toda maltratados, escarnecidos, na rua e dentro de casa" (DAMATA, 1975, p. 206). O preconceito não está na minoria e sim no outro, no grupo socialmente favorecido por ser o mantenedor da ordem, por não gostar ou não aceitar que cada um viva da forma como queira para experienciar a felicidade.

O desfecho a que chega o conto, assim como em Fábula, é com uma punição para a exposição, uma vez que José Tércio é assassinado, ou crucificado por suas escolhas, se é que ele escolheu em algum momento ser vítima de violência, preconceito, intolerância. A liberdade é o principal objetivo de viver, ser livre é o desejo de muitos indivíduos com os quais convivemos: não precisar mentir, não viver uma farsa, não esconder os seus desejos mais recônditos, o que lhe inspira a vida. Por vezes, ser livre custa um preço muito alto.

O que está posto nos textos de Damata nos faz pensar que transferir a sexualidade do âmbito do privado para o do público só se faz 
necessário por causa da representação das minorias, por causa das politicas públicas. Nesse sentido, o sair do "armário" pode significar, de fato, não sair para lugar nenhum, sair do "armário" para estar preso numa redoma de vidro, em que todos podem ver a subjetividade do individuo exposta, mas este nem sempre poderá se juntar aos demais.

\section{Considerações finais}

Diante da análise empreendida, pudemos confirmar a ideia de que não se pode falar em uma única masculinidade, nos levando a sair desse universo imposto socialmente em que o homem é somente aquele ser viril. O que temos nos contos é a presença de homens que assumem performances que vão além deste eixo: alguns são sensiveis, outros são ciumentos, há ainda os que temem o que os outros individuos possam pensar deles, os que vivem sob o domínio da família ou de seus amores.

Os solteirões nos proporciona conhecer, via ficção, o que se passa na sociedade carioca da década de 1970 e que se percebe ainda nos dias atuais: as possibilidades de ser além do que está imposto socialmente, tendo em vista que, por mais que percebamos existir uma variante que se quer dominante, o que os estudos apontam são as masculinidades que acolhem cada individualidade dos sujeitos masculinos, nas relações entre iguais ou não.

No que diz respeito ao "armário", o que 
apreendemos é que estar/permanecer/sair deste lugar, para os sujeitos do universo construído por Damata, está relacionado à conveniência, não no sentido de covardia, mas no sentido de preservar a subjetividade do sujeito. O que se percebe, ao final da leitura, é que o desejo de sair ou não do "armário" está mais para o interlocutor do que para a satisfação pessoal.

De um modo geral, os sujeitos confessam suas experiências àqueles que fazem parte de sua zona de conforto, outras vezes coagidos a sair do "armário", e raras são as vezes em que, de fato, adotam uma postura subjetiva diante da sociedade. Assim, pudemos confirmar que as relações estabelecidas entre os sujeitos gays e o "armário" são resultantes da imposição dos grupos detentores do poder e não provenientes do desejo de cada um de se assumir enquanto sujeito sexual e de gênero. 


\section{Referências}

BADINTER, Elisabeth. XY: sobre a identidade masculina. Tradução de Maria helena Franco Martins. Rio de Janeiro: Nova Fronteira, 1993.

DAMATA, Gasparino. Os solteirões. Rio de Janeiro: Pallas, 1975.

HOWES, Robert. Solidão e relações de poder na obra de Gasparino Damata. In: COSTA, Horário et al. (Org.). Retratos do Brasil homossexual: fronteiras, subjetividades e desejos. São Paulo: Editora da USP; Imprensa Oficial, 2010.

KATZ, Jonathan Ned. A invenção da heterossexualidade. Tradução de Clara Fernandes. Rio de Janeiro: Ediouro, 1996.

NOLASCO, Sócrates. O mito da masculinidade. Rio de Janeiro: Rocco, 1993.

. Um homem de verdade. In: CALDAS, Dário (Org.). Homens. São Paulo: SENAC, 1997.

PERLONGHER, Néstor Osvaldo. O negócio do michê: prostituição viril em São Paulo. São Paulo: Brasiliense, 1987.

PRECIADO, Beatriz. Multidões queer: notas para uma política dos anormais. Estudos Feministas, Florianópolis, v. 19, n.1, p. 11-20, jan.-abr. 2011. 
SILVEIRA, Micaela Sá da. As masculinidades no conto Paraíba, de Gasparino Damata. In: ANAIS DO IV CONGRESSO INTERNACIONAL DA ABRALIC, 13, 2013, Campina Grande. Campina Grande: UFPB, 2013 v. 1.

SEDGWICK, Eve Kosofsky. A epistemologia do armário. Cadernos Pagu, Campinas, n. 28, p. 19-54, jan.-jun. 2007. 